\title{
Correction to: Neolithic phylogenetic continuity inferred from complete mitochondrial DNA sequences in a tribal population of Southern India
}

\author{
Charles Sylvester ${ }^{1,2}$ (1) $\cdot$ Mysore Siddaiah Krishna ${ }^{1} \cdot$ Jaya Sankar Rao $^{2} \cdot$ Adimoolam Chandrasekar $^{2}$
}

Published online: 10 September 2018

๑) Springer Nature Switzerland AG 2018

\section{Correction to: Genetica}

https://doi.org/10.1007/s10709-018-0030-2

Unfortunately, the original version of this article was published with an error in the second sentence of the 'Molecular dating' section: "The first mutation rate based on substitution rate of the entire coding region...... was mentioned as 5.39 years for each mutation" (Mishmar et al. 2003).

However, the correct mutation rate is 5,139 years for each mutation (Mishmar et al. 2003).

\section{Reference}

Mishmar D, Ruiz-Pesini E, Golik P, Macaulay V, Clark AG, Hosseini S, Brandon M, Easley K, Chen E, Brown MD, Sukernik RI (2003) Natural selection shaped regional mtDNA variation in humans. Proc Natl Acad Sci 100(1):171-176

The original article can be found online at https://doi.org/10.1007/ s10709-018-0030-2.

Mysore Siddaiah Krishna

drosokrish@gmail.com

1 Department of Studies in Zoology, University of Mysore, Mysore, India

2 Anthropological Survey of India, Southern Regional Center, Mysore, India 